\title{
DETAILED STUDY OF SLOPE FAILURE IN ROCK
}

\author{
Suraj Tripathi \\ M.Tech, Department of Civil Engineering \\ Madan Mohan malviya university of technology, \\ Gorakhpur, U.P, India
}

\begin{abstract}
An earth slope is an unsupported, inclined surface of soil mass earth slopes are formed for railway formation, highway embankments canal. The failure of a slope may lead to loss of life and property and therefore it is essential to check the stability of proposed slope. In this paper the detail study of different failure of rock slope is being analyzed. The different failures are plain failure, wedge failure, Toppling Failure Circular Failure
\end{abstract}

Keywords - slope failure, type of rock failure, kinematics analysis of slope, slope stability, modes of failure

\section{INTRODUCTION}

The earth ground slopes vary from near zero to ninety degrees with the horizontal therefore natural slopes are omnipresent due to excavation man-made slopes are created because of construction activities such as roads, dams, buildings, waterways, and open cast mining. Natural slopes are common geological phenomenon occurring whenever the shear strength and shear stress imbalance in the ground these failures are triggered by slope and dependent process or brought about by extraneous factored in an abrupt manner also due to increase in the seepage pressure due to buildup of hydrostatic pressure such as tension crack excavation of the slope toe material etc. The instability occurs concluding all this the failures may be broadly categorized into (I) Rock falls and (II) Rock slides, both rotation and translational.

On various steep slopes, rock falls occurs when blocks of rocks get detached from the joint without sliding on a curved surface heavily fractured and weathered rock slopes may fail. On week bading or shear planes or along fault zones Occuring transnational slides tends to be planar. Therefore in general the depth of the falling mass increases with the increase of the slope angle. The basic difference in this slide is that the movement initiates rotational slides whereas imbalance in the forces results in the translational movement.

\section{TYPE OF FAILURE}

\section{A. Plain Failure:}

- The plane on which sliding occur must strike parallel or nearly parallel to the slope face palne. Simple plane

\author{
Annu Dubey \\ M.Tech, Department of Civil Engineering \\ Madan Mohan malviya university of technology, \\ Gorakhpur, U.P, India
}

failure is the easiest form of the rock failure to analyse its occurs. When discontinuity striking approximately parallel to the slope face and dipping at a lower angle intersects the slope face enabling the material above the discontinuity to slide.

- The plan on which sliding occurs must strike parallel or nearly parallel to slope face (with in approximately $\pm 20^{\circ}$ )

- The sliding plane must day light in the slope face which means that the dip of the plane must be less than the dip of the slope face that:

$$
\Psi p<\Psi f
$$

- The dip of the sliding plane must be greater than the angle of friction of this plane that is :

$$
\Psi p>\Phi
$$

- The upper end of the sliding plane surface either intersects the upper slope or terminates in a tension crack.

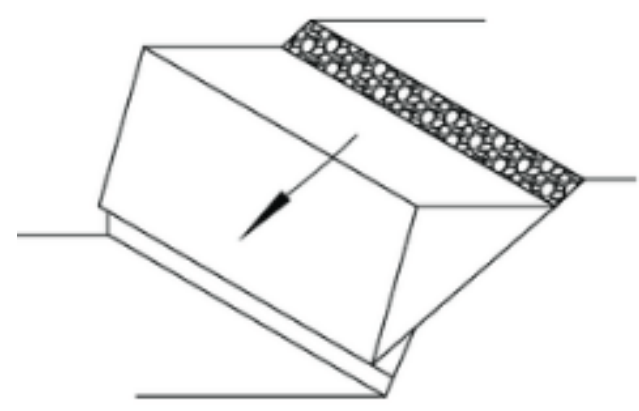

Fig. 1. Plain failure

\section{B. Wedge Failure:}

- The dip of the line of intersection must be greater than angle of internal friction.

- The dip of the line of intersection is smaller than dip of slope face.

- The two sets of discontinuities must intersect each other. 
- The sliding will take place along the dip of intersection of two discontinuities if the dip of the line of intersection day lights into the slope face and less than dip of the slope face.

- Wedge failure occur along two joints from different set with intersecting dip towards slope.

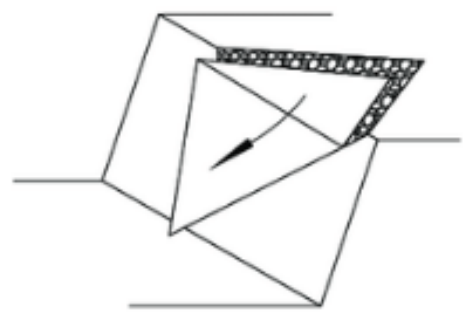

Fig. 2. Wedge Failure

\section{Toppling Failure:}

Toppling failure occurs long a prevalent and it continuous set of joint which dip against the slopes. With strike near parallel to slope face joint slips between then and is frequently weathered. Toppling involves rotation of columns or Block of rock about a fixed base.

[1] Block Toppling - When individual columns in a strong rock are formed by a set of discontinuities dipping steeply into the face a second set of widely spaced orthogonal joints defines the column height.

[2] Flexural toppling - Continuous columns of rock separated by well-developed steeply discontinuities breaking in failure as they bent forward typically geological conditions in which this type of failure may occur are thinly bedded shale and slate in which orthogonal in which orthogonal jointly is not well developed.

[3] Block flexural Toppling - It this long columns that are dividing by numerous cross joints. Toppling of columns in this case results from accumulated displacement on the cross joints. Because of the large number of small movement in this type of topple there are fewer tension cracks than in flexural toppling and fewer edge to face contacts and voids than in Block toppling.

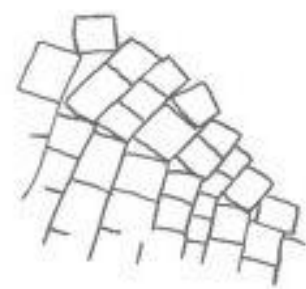

Fig 3. Block Toppling

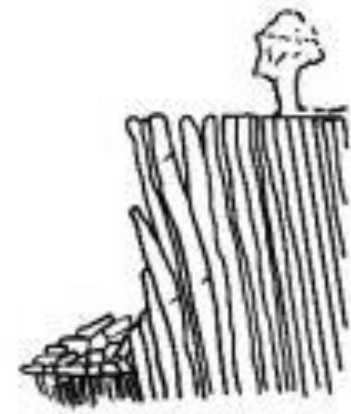

Fig 4. Flexural Toppling

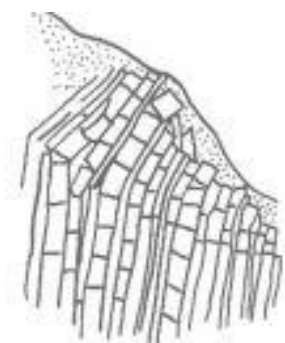

Fig 5. Block Flexural Toppling

D. Circular Failure- Closely fractural or highly weather rock. The slide surface is free to find the line of least resistance through the slope. When the individual particles in a soil or rock mass are every small compared with size of slope. Circular failure generally occurs in weak rock or soil slopes. Failure of this type do not necessarily occurs along a purely circular arc some form of curved failure surface is normally apparent. Circular shear failures are influence by the size and mechanical properties of the particle in the soil or rock mass. When the material is very weak as in tailing dump in soil slope or when the rock slope or when the rock mass is very heavily jointed or broken.

- Slope Failure - The arc of rapture surface meet the slope above the toe of slope. This happens when the slope angle is very high on the soil close to the toe posses the high strength.

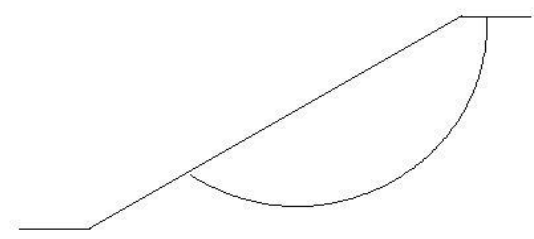

Fig 7. Slope Failure

- Toe Failure - The arc of rapture surface meets the slope at the toe at medium slope angle. 


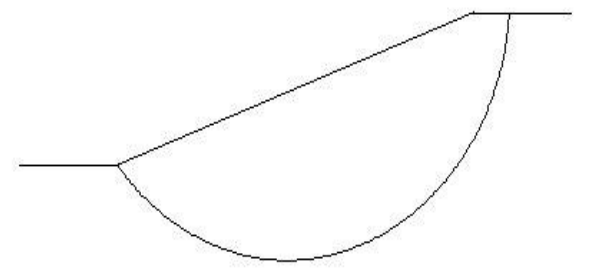

Fig 8. Toe Failure

- Base Failure - The arc of failure possess below the toe and into base of the slope this happens when the slope angle is low and the soil below the base is softer and more plastic than the soil above the base.

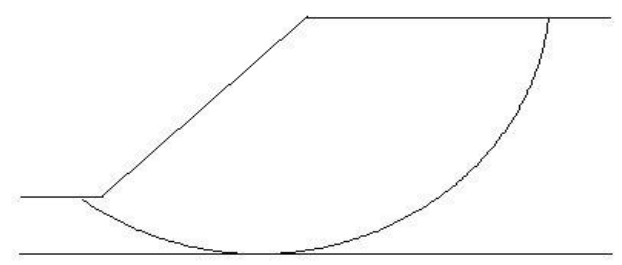

Fig 9. Base Failure

E. Step Path Failure - Step path failure is similar to plane shear failure but the sliding is due to combined mechanism of multiple discontinuities or the tensile failure of the intact rock connecting member of the master joint set.

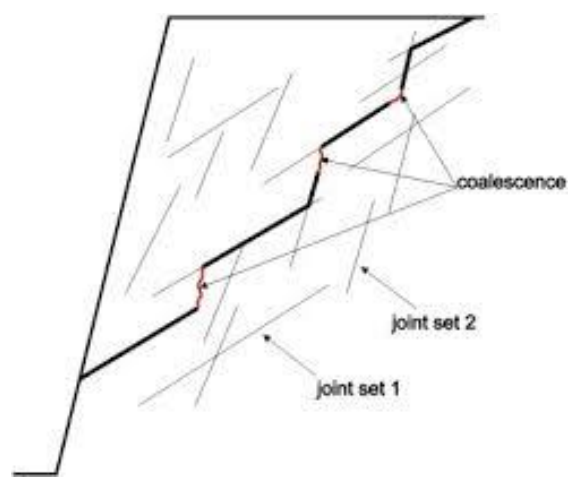

Fig 10. Step Path Failure

F. Reveling - Weathering of material and expansion and contraction associated with freeze thaw cycles are principle cause of reveling. This type of failure generally produces small rock falls not massive failure.

\section{CONCLUSION}

1. Understanding the slope stability parameters is very important for which different analyses is done.
2. We can use some computer programs for analyzing and simulation has become a common mode for different analysis. 3. Slope stability analysis is routinely performed to assess the safe design of a human made or natural slopes.

4. The analysis technique depends on both the site condition and potential mode of failure.

\section{REFERENCE}

[1] Santharam A. and Thote N.R. (2005), Slope Control in Intensely Weathered Rock Masses: Case study of Saniem (Sacorda)

[2] Iron Ore Mine, Goa , Proceedings of the National Seminar on Indian Mining Industry (IMID), Nagpur pp. 71-78

[3] Santharam A. and Thote N.R. (2008), Pit Slope Failure Problems in Goan Iron Ore Mines, Goa, India:, 6th International

[4] Conference on Case Studies in Geotechnical Engineering, Arlington, Virginia, USA

[5] Santharam A., Dr Thote N.R. and Dr Jethwa J.L. (2010), Applications of Risk Management Techniques for Assessment of Rock Slope Engineering Problems "Applications of Rock Mechanics -Tools and Techniques". Nagpur, pp. 1-12

[6] Robertson, A. Mac G (1971), Determination of Stability of slopes in jointed rock with particular reference to the determination of strength parameters and mechanism of failure. Ph.D. thesis, University of the Witwatersrand

[7] Robertson A. and Mac G. (1988), Estimating Weak Rock Strength AIME Annual General Meeting, Tucson, Arizona, USA

[8] Serafim J.L. and Periera J.P. (1983), Considerations on the Geomechanics Classification of Bieniawski Int.Symposium Eng.Geology, Lisbon, Vol. 1, pp. 131142

[9] De Freitas, M. H. \& Watters, R. J. (1973). Some field examples of toppling failure. Geotechnique 23, No. 4, 495-514. I

[10] Duran A, Douglas K. Experience with empirical rock slope design. In: proceedings of ISRM International Symposium; 2000.

[11] Goodman, R. E. (1976). Methods of geological engineering in discontinuous rocks. St Paul, Mn: West.

[12] Goodman, R. E. (1989). Introduction to rock mechanics, 2nd end. New York: Wiley.

[13] Goodman, R. E. \& Bray, J. W. (1977). Toppling of rock slopes. Proceedings of specialty conference on rock engineering for foundation and slopes, vol. 2, 201- 234.

[14] T.Ramamurthy, (2011), $2^{\text {nd }}$ edition stability of rock slopes, pp. 320-358

[15] Indian bureau of mines, (2014) $1^{\text {st }}$ edition, pp.55-58. 